\title{
MODELLING OF THE TRAFFIC FLOW BASIC CHARACTERISTICS AT THE ROAD NETWORK SELECTED SECTION
}

\author{
Alica Kalašová*, Simona Skřivánek Kubíková, Veronika Harantová \\ Department of Road and Urban Transport, Faculty of Operation and Economics of Transport and Communications, \\ University of Zilina, Zilina, Slovakia \\ *E-mail of corresponding author: alica.kalasova@fpedas.uniza.sk
}

\begin{abstract}
Resume
Elimination of connection between an increase in transport and economic growth has been the main aim of the transport policy of the EU for a few years and it has not been accomplished yet. Transportation causes considerable external costs that have concrete originators but are not paid by them. The biggest external costs are connected with emissions, noise, accidents and congestions. In this contribution, the problem of congestions, which currently bother drivers in EU was analysed, together with possibilities for their solving, since the congestions' reduction is one of the priorities of the EU's transport policy. The task was to observe a relation between the basic traffic flow characteristics on the specific section of the road no. I/65 and to identify effects on traffic in general, as well as to specify reasons and conditions within the traffic congestions that occurred. These results are a basis for the theoretical proposal of possible solutions of the issue.
\end{abstract}

\section{Article info}

Received 9 April 2020

Accepted 19 June 2020

Online 3 November 2020

\section{Keywords: \\ road safety, external costs, congestions, traffic flow}

\section{Introduction}

Reduction of external costs is one of the most significant factors affecting increase in the road transport safety. External costs are described as follows. When consumers decide to purchase an item or take a trip, they examine the price of a given option and compare it to the gain or satisfaction they expect. For example, a person who wants to get from place A to place B will consider the price (of using public transport or his/her private car) and quality of the service provided before choosing the suitable transport mode. Users are willing to accommodate a whole array of parameters (speed, frequent/regular service, quality, flexibility, etc.) in the price of transportation that users pay. Consumers of goods or services do not generally foot the full bill for the costs that their decision imposes on society and the environment. These costs are defined as external because they are not reflected in the price paid by users. The main sources of external costs in the transport sector are accidents, congestions, air pollution, noise and climate changes [1-2]. This paper is focused on the congestions that are probably the most negative phenomenon that drivers perceive while driving. The main aim was to try to specify the connections between traffic flow characteristics and why congestions occur. It was decided to observe the traffic characteristics' relationships at the selected section of the road no. I/65. The first part of the paper includes some theoretical knowledge about the traffic flow theory. The next part includes a description of the selected road section, methodology and results of transport survey using the Sierzega microwave radar. Based on those findings, the last part consists of discussion and formulated conclusions.

\section{Literature preview}

Since the 1960s of 20th century, the generalized relationships between speed, density and the flow rate are defined with the following parameters [3]:

Flow Rate (intensity) - number of vehicles per hour, which pass over a given point or section of a lane or roadway during a given time interval of less than one hour.

Speed - defined as a rate of motion expressed as a distance per unit of time, generally as kilometre per hour $(\mathrm{km} / \mathrm{h})$. In characterizing the speed of a traffic flow, a representative value must be used, because a broad distribution of individual speeds is observable in the traffic flow.

Density - the number of vehicles occupying a given length of a lane or roadway at a particular instant. Density is usually expressed as vehicles per kilometre (veh/ $/ \mathrm{km})$.

While diagrams in Figure 1 show continuous curves, in reality there are likely discontinuities, with part of these curves not present. The curves illustrate the following significant points: 

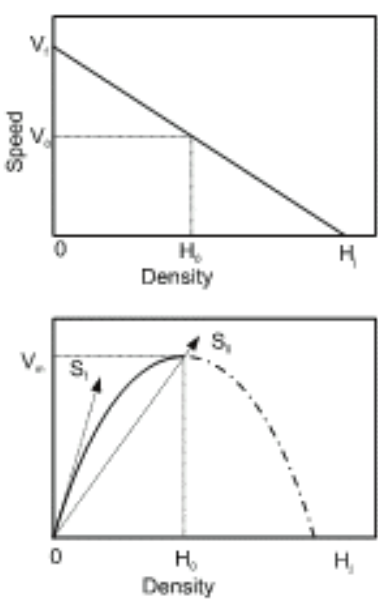

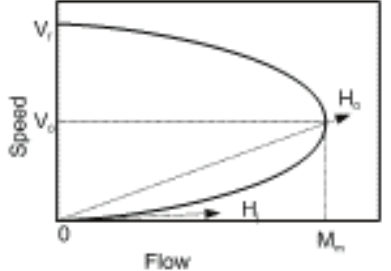

Flow

Legend

-.... Oversaturated flow

Figure 1 Basic relationships between the traffic flow characteristics [3]

A zero flow rate occurs under two different conditions. One is when there are no vehicles on the facility - density is zero and a flow rate is zero. The second is when density becomes so high that all the vehicles must stop - the speed is zero and the flow rate is zero, because there is no movement and vehicles cannot pass a point on the roadway.

Between these two extreme points, dynamics of the traffic flow produces a maximizing effect. As flow increases from zero, density also increases, since more vehicles are on the roadway. When this happens, speed declines because of the interaction of vehicles. This decline is negligible at low and medium densities and flow rates. As the density increases, these generalized curves suggest that speed decreases significantly just before a capacity of the road is reached. The capacity is defined as the product of density and speed resulting in the maximum flow rate. This conditions are shown as optimum speed $\mathrm{V}_{0}$ (often called critical speed), optimum density $M_{o}$ (sometimes referred to as critical density) and maximum flow $\mathrm{V}_{\mathrm{m}}$.

In accordance with NI [4], the traffic demand is not constant. It can vary significantly depending on the season of the year, the day of the week and even the time of the day. In addition, the capacity is not constant - it can change (sometimes rapidly) because of weather, work zones, traffic incidents, or other events. It is not necessarily simple, either. The physical fact of finiteness and the principle of conservation underlie the traffic stream behaviour. However, the actual performance of a particular section of a freeway, at a particular point in time, is more ambiguous, resulting from variations in individual human behaviour and the mix of vehicle types using the facility. According to KESSELS [5], it may be possible to predict the average behaviour and average capacity and the variances about these averages for a traffic flow, but never the precise behaviour.

The principles of macroscopic models are relations between the essential characteristics of a traffic flow intensity, density (quantitative characteristics) and speed (a qualitative characteristics). For a complete description, only two of these characteristics are sufficient, the third one can be calculated according to an equation of continuity [6-7]:

$\mathrm{M}=\mathrm{H} . \mathrm{V}$ [veh/h],

where:

$\mathrm{M}$ - intensity [veh/h],

$\mathrm{V}$ - speed $[\mathrm{km} / \mathrm{h}]$,

$\mathrm{H}$ - density [veh/km].

The theory of traffic flow recognizes two types of movements:

- movements of one vehicle,

- movements of a group of vehicles in the same driving lane.

\section{A movement of vehicles within a different driving lanes layout}

Vehicles change their position during the driving in a certain direction, depending on width conditions, density, speed etc. Different modes of vehicles' behaviour in the traffic flow can be derived from these conditions:

- $\quad$ stream driving in a single lane in a row (overtaking is not possible),

- driving where overtaking is possible (without any issues on the unidirectional two - lane belt, sufficient space in opposite direction on the two - lane belt),

- changing driving lanes on multiple-lanes belt (it is possible in several driving lanes, overtaking in the right lane is dangerous),

- vehicles movements on the two or four lane bi-directional belt (it gives an option of various movement conjunctions; traffic flow imbalance could create danger) $[4-5,8]$.

Driving of vehicles in a stream

While driving, the situation of vehicles' movements changes (a number of vehicles, speed, structure of traffic flow, weather, etc.). A stream of vehicles is made up of two or more vehicles driving behind each other in the same 


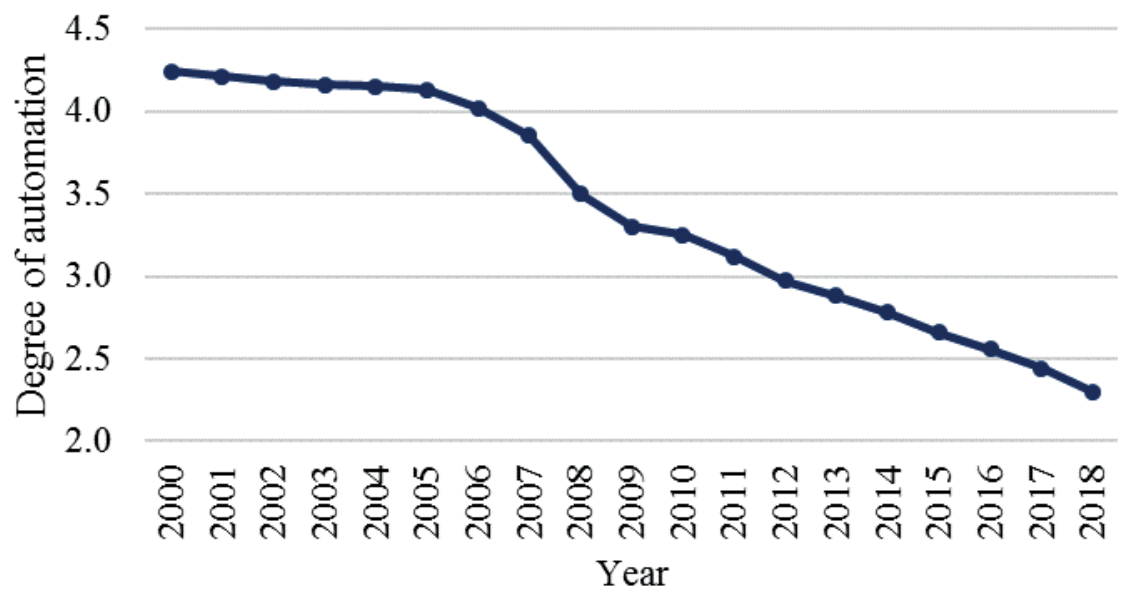

Figure 2 Development of the degree of automation in Slovakia (based on data from the Statistical Office of the SR) [16]

driving lane. Driving is disturbed and has its own specifics, it is different in non - urban areas and in urban areas. It is possible to determine:

- a number of vehicles in a stream - speed of the stream, defined as an average travel speed determined from speed of each vehicle in a stream,

- time consuming of a stream, defined as a difference in passage time of the first and the last vehicle of a stream in the chosen road profile,

- a physical length of a stream, defined as a distance among the first and the last vehicle at the same moment,

- a stream dispersion expressed as a relative change in time and length dimensions of a stream, which is related to a particular profile of a road communication or time point [3, 9-10].

\section{Methods and materials}

Currently, the road network of $38985 \mathrm{~km}$ of length is used in the Slovak Republic [11]. Regarding increasing intensities mainly on highways and I class roads, the character of traffic departs from the free traffic flow and the proportion of traffic increases with the degree of load, which is approaching value of 1 . In this case, individual vehicles affect each other in the traffic flow. In the Slovak republic, in 2018 the number of registered vehicles increased by $4.16 \%$ compare to 2017 and reached the value of more than 3.2 million. The increase of individual automobiles (IA) was $4.24 \%$ and exceeded 2.3 million [12-13], which represents a degree of automation of 2.34, see Figure 2.

Time losses resulting from congestions are a significant negative effect of overloaded roads, which affect the economic activity of inhabitants indirectly. While in 2000, there was one individual car per 4 inhabitants, in 2018 it was already one IA (individual automobile) per 2.3 inhabitants. One of the significant parameters, which have an impact on individual automobile transportation increase, is rising of the living standard of population and increasing demands on the expected quality of transport [14-15].

The situation in freight transport does not contribute to improving the overall situation either. While the importance of transport modes, suitable for transport of large volumes of goods, without undue burden on infrastructure and the environment, is decreasing or is totally negligible in the total transport volume, transport performances of the road freight transport are rising steeply. Figure 3 presents development of the modal split of the freight transport in Slovakia [14, 17].

Taking into account all of these mentioned issues, it is very important to know and understand theory of the traffic flow and be able to predict under what conditions do congestions occur.

\subsection{Methods of traffic flow monitoring using Sierzega microwave radars}

The microwave radar Sierzega was used since the idea was to measure the basic traffic flow characteristics.

Radars have recorded vehicles' passage in real time, speed, length and direction of vehicles (this value is recorded only when bidirectional measurement is turned on but it is very inaccurate at higher intensities). The most accurate results are obtained for a single lane road communications. For the multiple lane communications, accuracy declines as traffic flow increases because of the vehicles overlapping. The main reason of this accuracy decline is an implementation of the radar low above the road (see Figure 4), as well as the measurement is running under the angle of $30^{\circ}$ and any deviation reduces accuracy, e.g. determination of a vehicle length. Measurement accuracy deviations are according to the manufacturer: speed \pm $3 \%$, length of vehicle $\pm 20 \%$, space between vehicles \pm 0.2 s. Another disadvantage is the range of a measurement. A manufacturer declares the range of measurement from 8 to $254 \mathrm{~km} / \mathrm{h}$. However, at lower speeds there is a large measurement deviation in the number of recorded vehicles. 


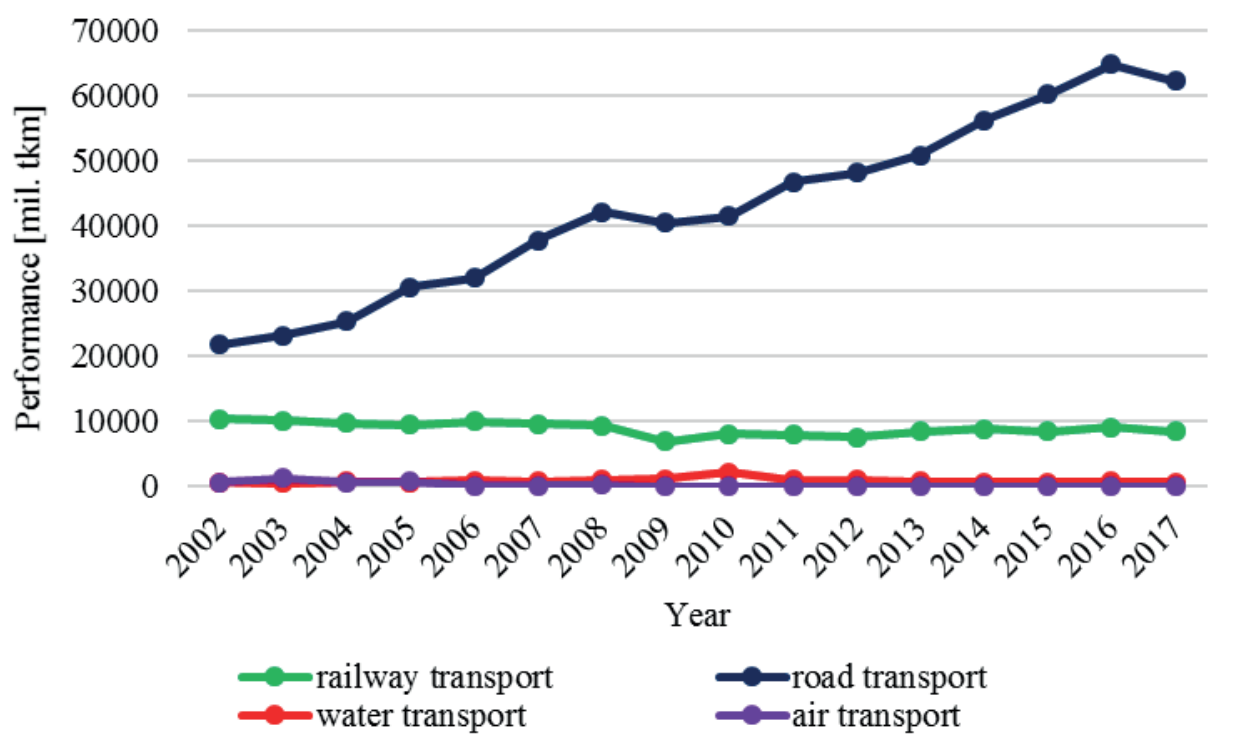

Figure 3 Modal split of freight transport in Slovakia (based on data from the Statistical Office of the SR), [16]
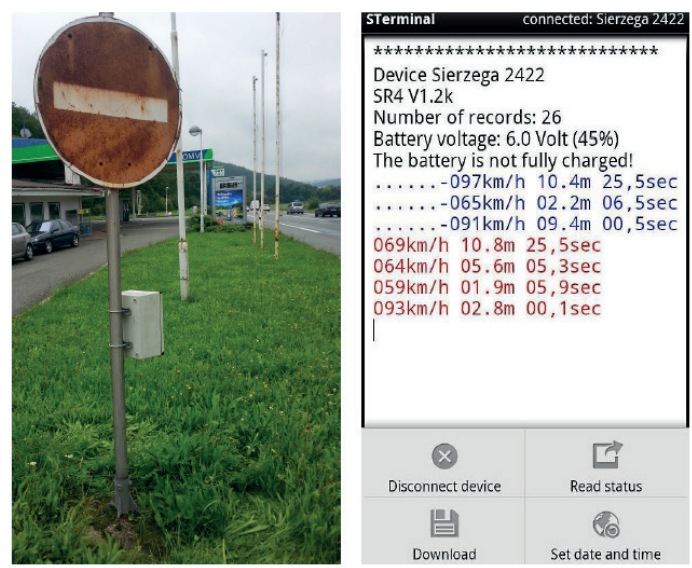

Figure 4 Radar Sierzega, on the left - hand: implementation of the radar on the traffic sign; on the right - hand: the example of reached data from radar [18]

An advantage of this device is its mobility, due to small dimensions $400 / 400 / 200 \mathrm{~mm}$ and a big range of operating temperatures from $-20{ }^{\circ} \mathrm{C}$ to $60{ }^{\circ} \mathrm{C}$ [18-19].

\subsection{An analysis of the selected section of road communication}

The basis of a research are the transport surveys and their detail analysis, where the data obtained from the radar Sierzega were used, specifically vehicles intensity and travel speed. The vehicles density was calculated using the equation of continuity (1). The main objective of this research was to better understand the behaviour of a traffic flow as well as the relations between vehicles [19-20].

The measurement was carried out on Tuesday, $17^{\text {th }}$ of September 2019 in cadastral city of Martin on the I class road I/65, see Figure 5. The transport survey took 12 hours, from 6 a.m. to 6 p.m. The maximum permitted speed on the chosen section is $50 \mathrm{~km} / \mathrm{h}$.
During the measurement, the intensity reached 13505 vehicles per 12 hours, in both directions. The highest value of the intensity 326 vehicles per 15 minutes, was recorded from 6:30 a.m. to 6:45 a.m. and the peak hour of 1248 vehicles per hour was recorded from 6:30 a.m. to 7:30 a.m. The structure of the traffic flow, according to obtained data, is as follows:

76.3\% IA (individual automobile), 10.5\% T (Truck), $12.5 \%$ HT (Heavy Truck), 0.37\% M (Motorcycle), $0.25 \%$ Bus and $0.07 \% \mathrm{~B}$ (bicycle).

This is the case of the inhomogeneous traffic flow, because it is predicted that for the homogenous traffic flow a minimum of $80 \%$ of vehicles, which have similar properties, is needed (e.g. individual automobiles). The data were divided in accordance with the driving lanes and then speeds and intensities of all the modes of transport were generated. Subsequently, the vehicle densities were determined. Based on that, the following diagrams were created, see Figure 6. [22] 


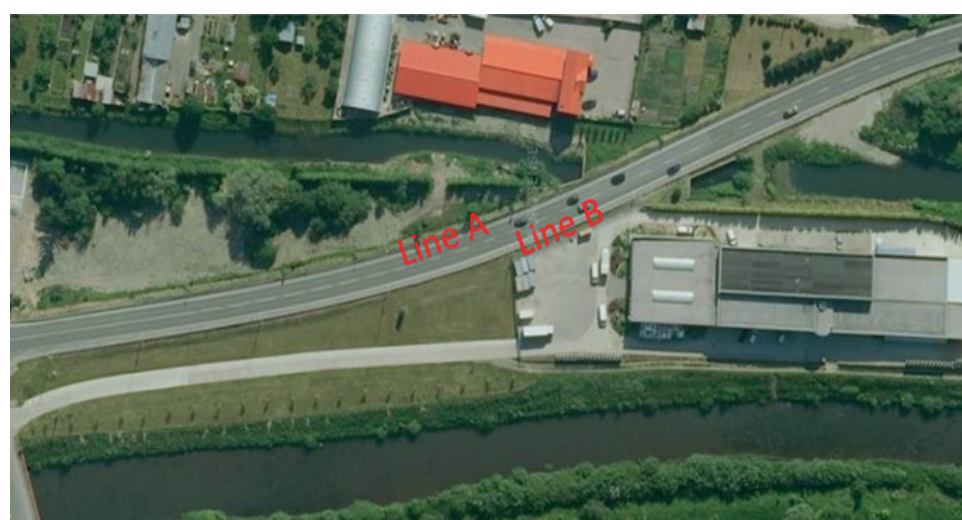

Figure 5 The chosen section of road I/65 (based on use of the Openstreet maps) [21]

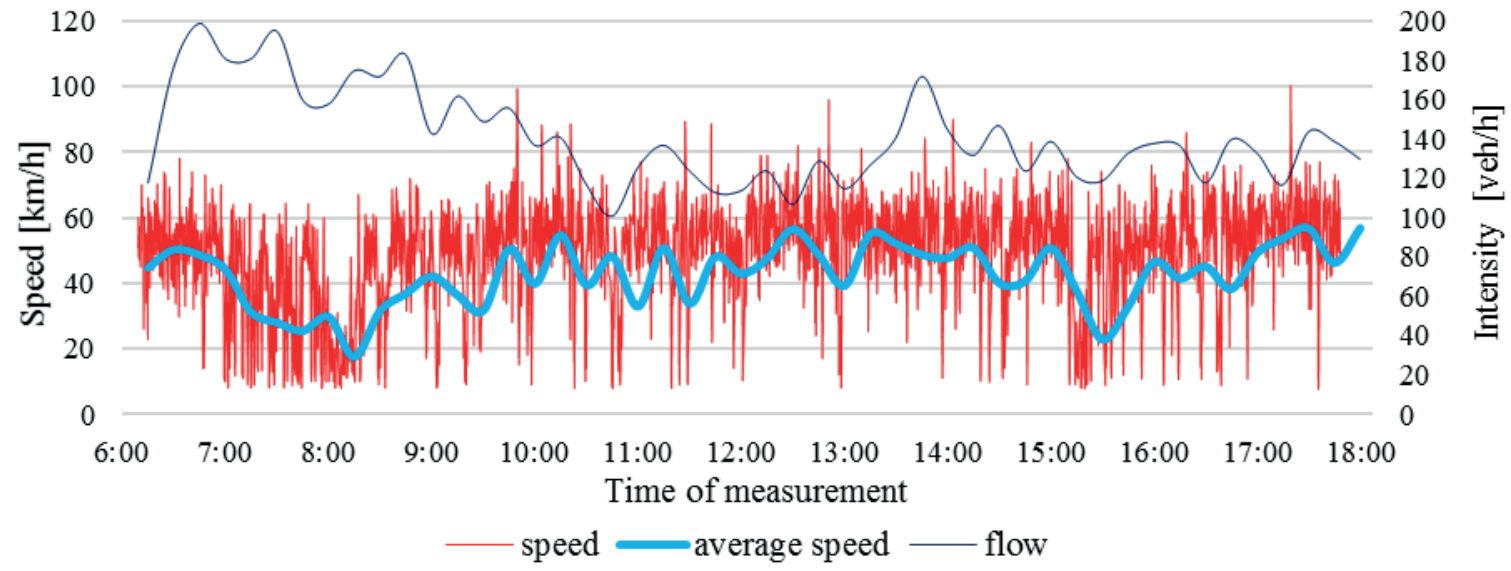

Figure 6 Running of real vehicles speed and an average vehicles speed during the 15 minutes intervals in the traffic flow measurement on the lane $A$

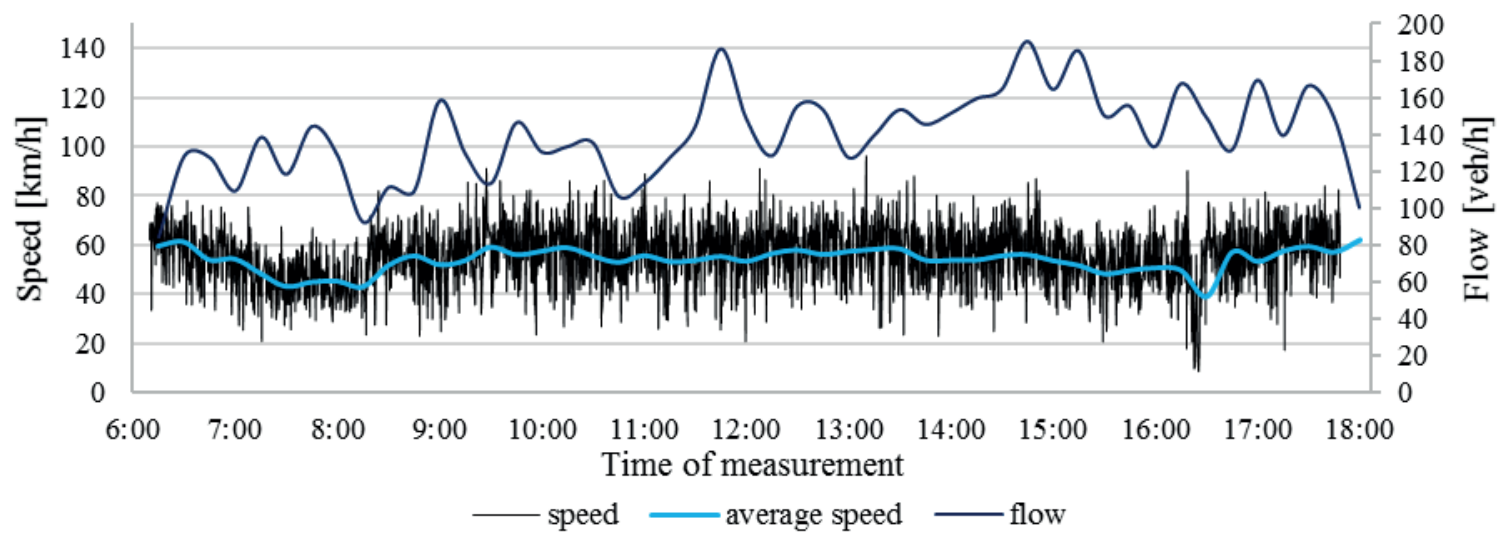

Figure 7 Running of real vehicles speed and an averaged vehicle speed during the 15 minutes intervals in the traffic flow measurement on the lane $B$

Figure 6 shows that the decrease of vehicles speed was recorded on driving lane A twice approximately at 8 a.m. and in the afternoon at 3 p.m. The highest intensity was recorded at 6:45 a.m. and it gradually declined and then slightly increased again at 1:45 p.m. An average vehicle speed reached value of $54 \mathrm{~km} / \mathrm{h}$ during the measurement.

The velocity curve on the second lane in the opposite direction, Figure 7, has the lower velocity dispersion than in the first case. However, it can be seen that most vehicles exceeded the speed limit. In this case, the intensity sharply varies. The lowest value was recorded at 8:15 a.m. and, on the other side, the highest value intensity was recorded at 2:45 p.m. An average speed of vehicles reached $42 \mathrm{~km} / \mathrm{h}$.

Figure 8 shows the intensity, speed and average speed for both driving lanes. The intensity for both directions first raised sharply and then oscillated around 300 vehicles per hour. The decline occurred at 10:45 a.m., but then the intensity value began to increase and exceeded again 


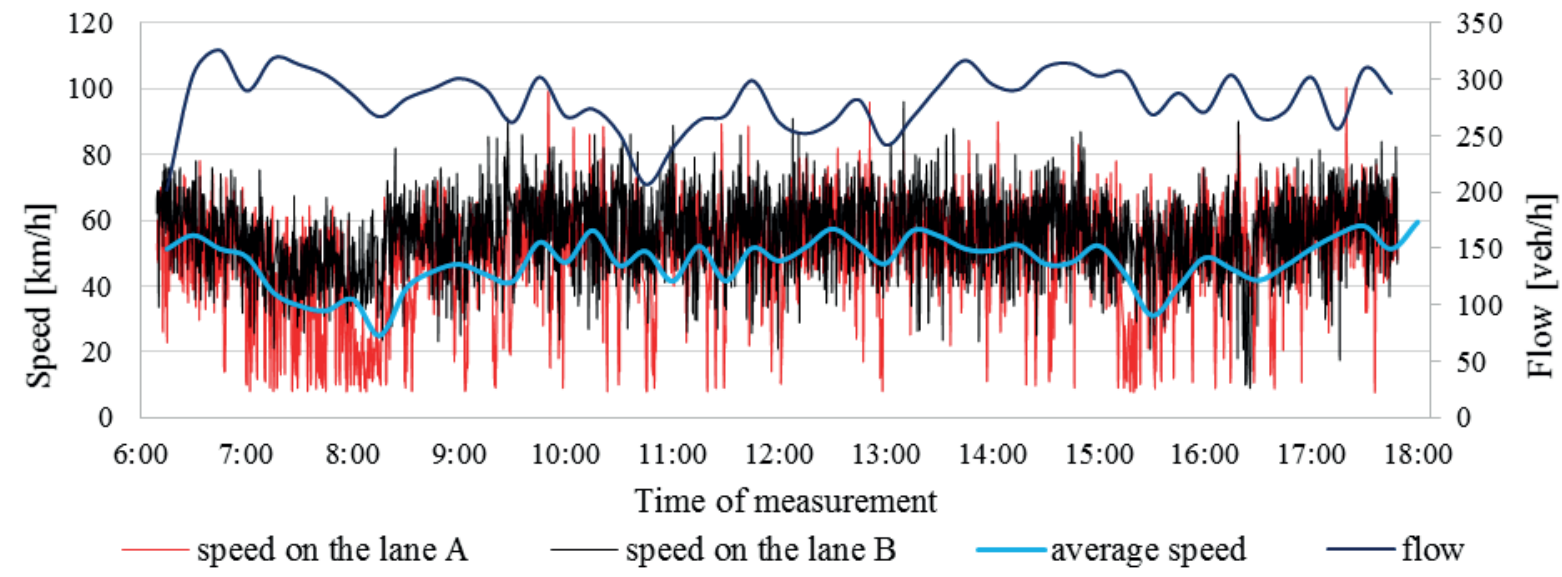

Figure 8 Running of real vehicles speed and an average vehicle speed during the 15 minutes intervals in the traffic flow measurement on both lanes

Lane A

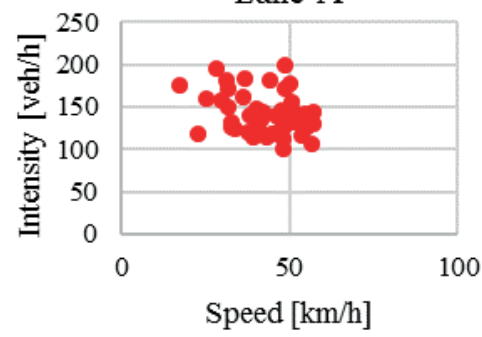

Lane B

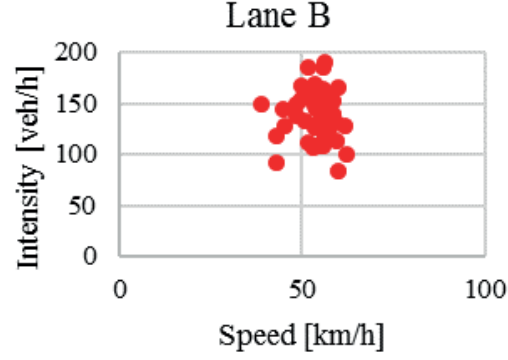

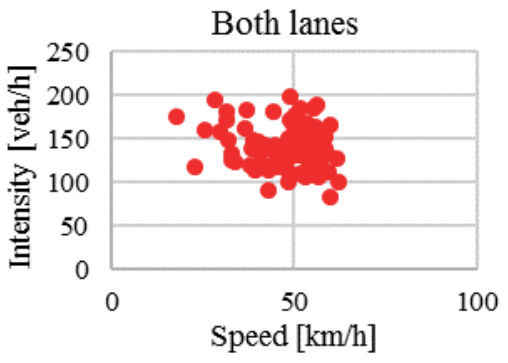

Figure 9 Graphical dependence between the traffic flow intensity and speed
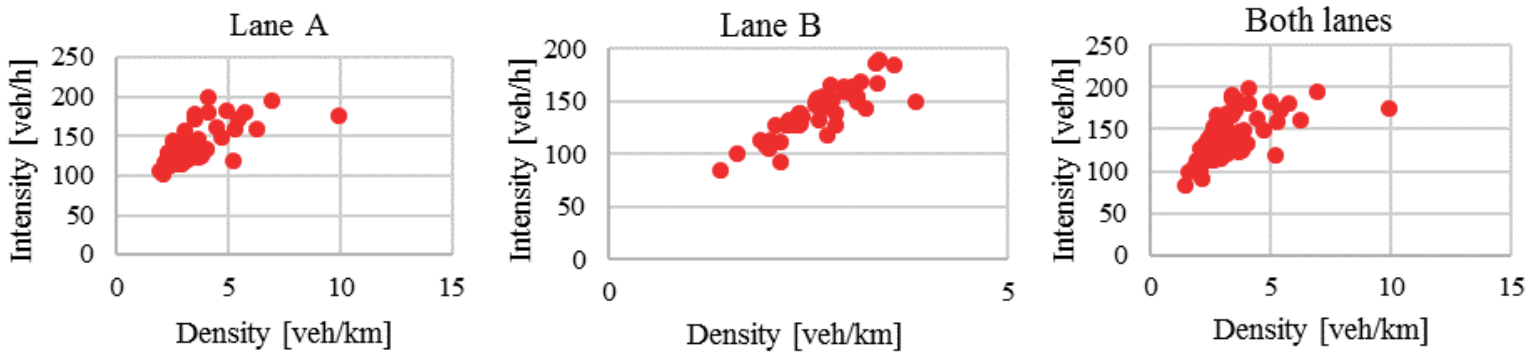

Figure 10 Graphical dependence between the traffic flow intensity and density

value of 300 vehicles per hour. The average speed on the monitored section during the measurement reached 45 $\mathrm{km} / \mathrm{h}$.

The dependence should create a parabola according to basic relation (Figure 1). However, with increasing speed the intensity should also increase, which represents a linear course. From several points of view, it is obvious that each intersection or communication has maximum capacity. If this capacity were exceeded, intensity should still rise and a speed is decreasing, see Figure 9. The maximum capacity was reached at the optimum speed and due to declining speed intensity it starts to decrease and leads to reducing the gaps between vehicles and increasing density.

Therefore, the relation between intensity and speed is expressed as a parabola. The same rule applies also for intensity - density relation (Figure10).

Correlation coefficient between parameters, shown in Figure 10, also refuted the linear dependence. The value of this coefficient was in range of -0.299 to -0.037 , which corresponds to very weak linear dependence. However, an interesting thing is that dependence between the intensity and density (Figure 10) became a linear dependence with a high correlation coefficient of 0.653 and 0.859 , which is the middle and strong correlation.

The dependence between speed and density has, on the other hand, an exponential running with a confidential level of almost $80 \%$ (Figure 11). In principle, if vehicles speed would decrease, the density at the chosen monitored road section would rise and vice versa.

Figure 12 presents dependence of the basic characteristics during each hour of measurement. Between the speed and density, a linear course is very noticeable; if one quantity decreases the other increases and vice versa. The intensity also corresponds to this fact. When the speed decreases, the intensity of vehicles is also decreasing and vice versa 

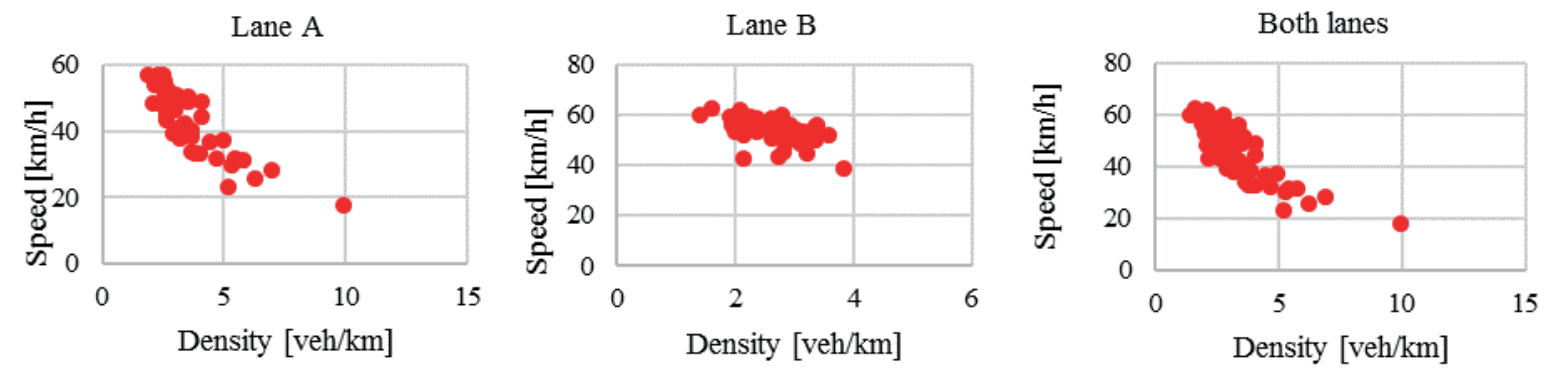

Figure 11 Graphical dependence between the speed and the traffic flow density

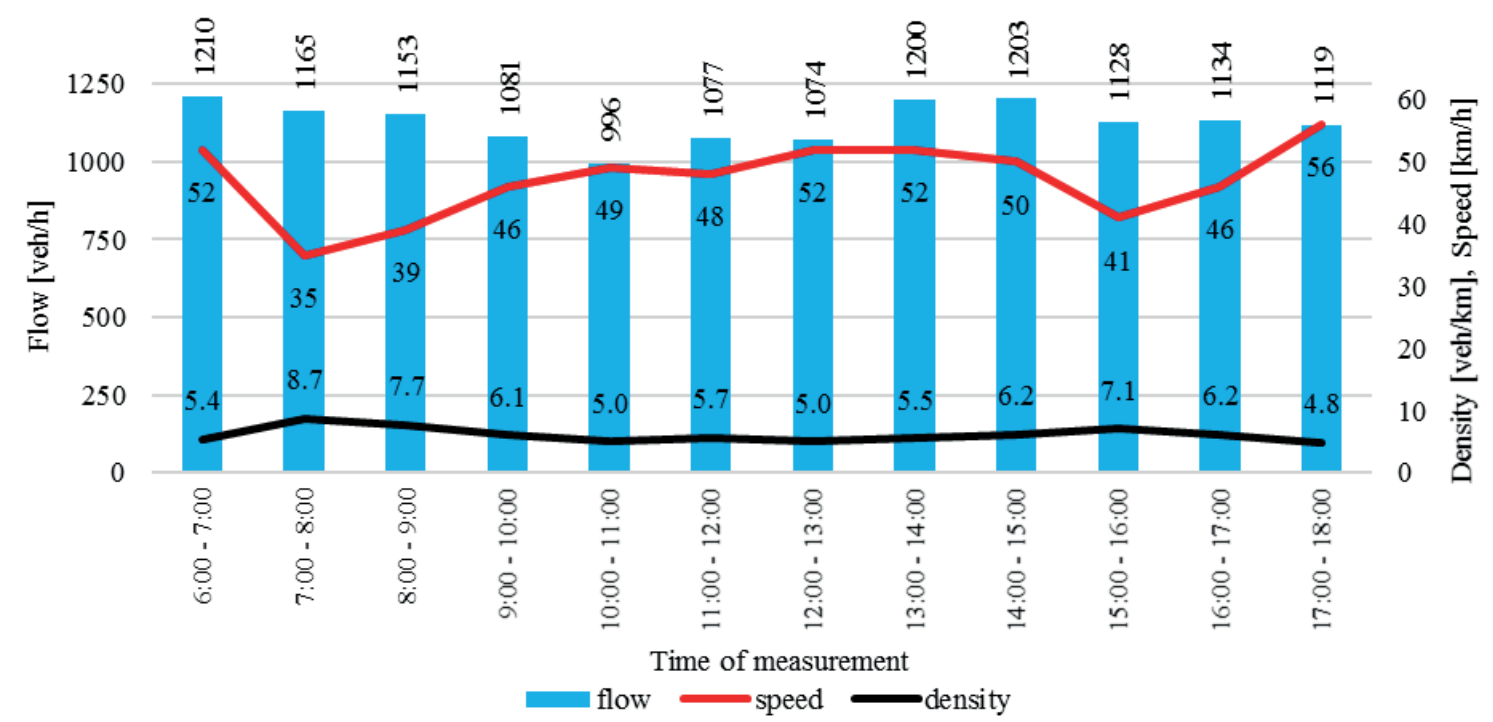

Figure 12 Running of the basic traffic flow characteristics related to one-hour gap intervals

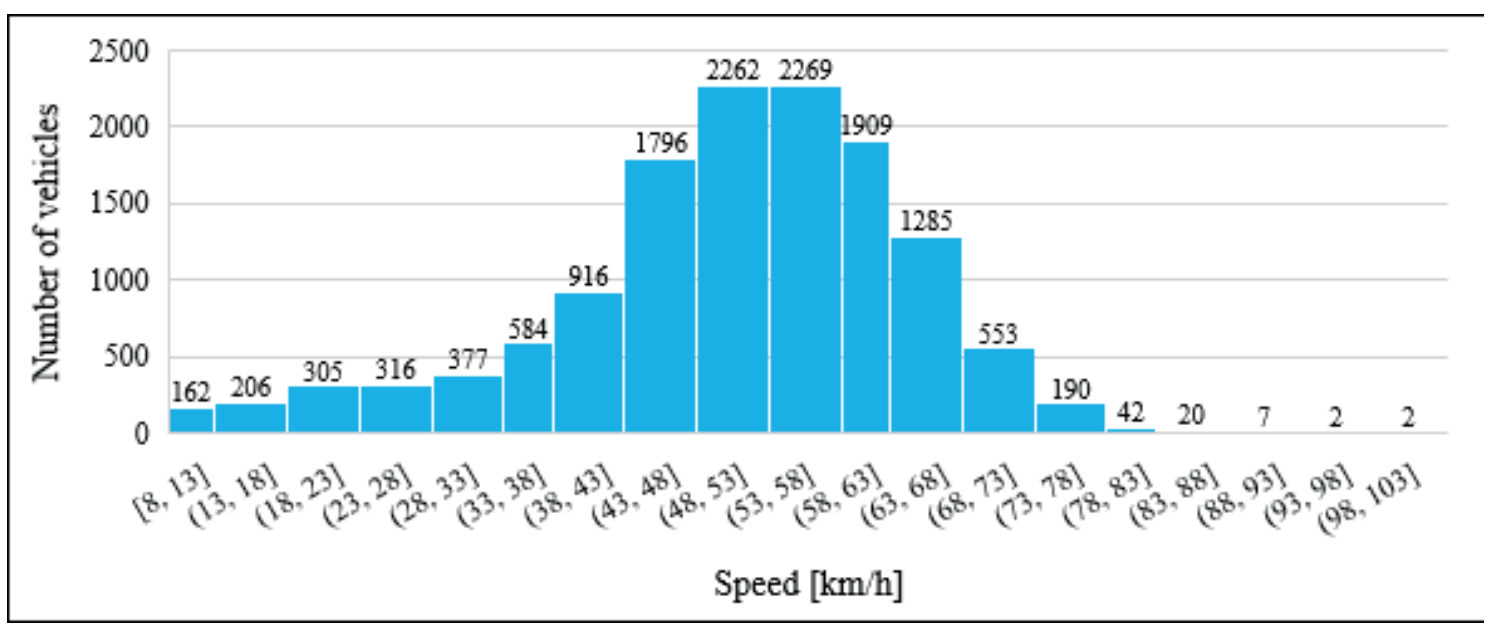

Figure 13 Division of vehicles' speeds according to their frequency

The correlation coefficient was calculated also for the speed/ density relation. In this case, the correlation coefficient of dependence between the two parameters is 0.963 , which represents a very strong negative correlation.

\subsection{Histograms of observing variables}

Histogram is a graphical representation of data distribution using the column graph, with columns of the same width, which represents the width of intervals, while the height of column shows a frequency of a monitored variable in the given interval. It is important to choose the suitable width for an interval, because the incorrect width can decrease information value of a histogram.

The range of one class is $5 \mathrm{~km} / \mathrm{h}$ and there are 20 different classes. Figure 13 shows that the lowest recorded speed of vehicles was $8 \mathrm{~km} / \mathrm{h}$ and the highest one was 103 $\mathrm{km} / \mathrm{h}$. The range of recorded speeds is $95 \mathrm{~km} / \mathrm{h}$. These data on speed are generated by the radar, which was used for 


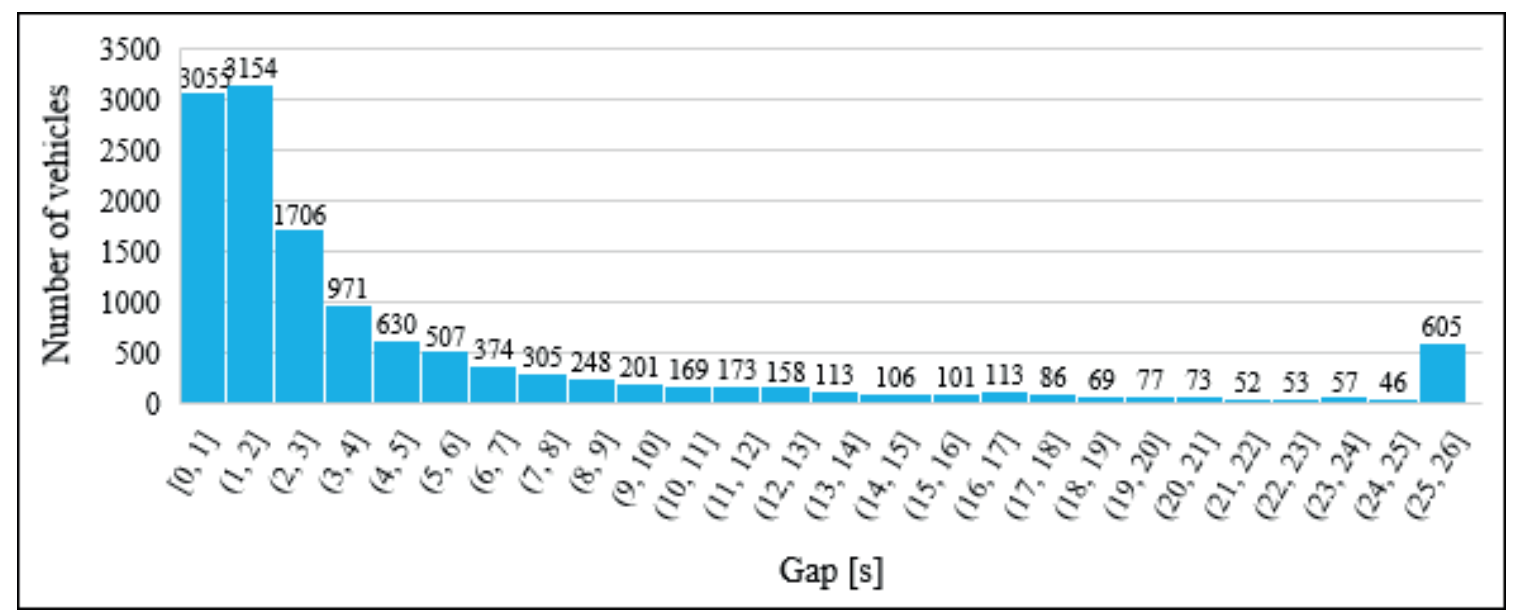

Figure 14 Division of time gaps to 26 classes with range of one class of $1 \mathrm{sec}]$

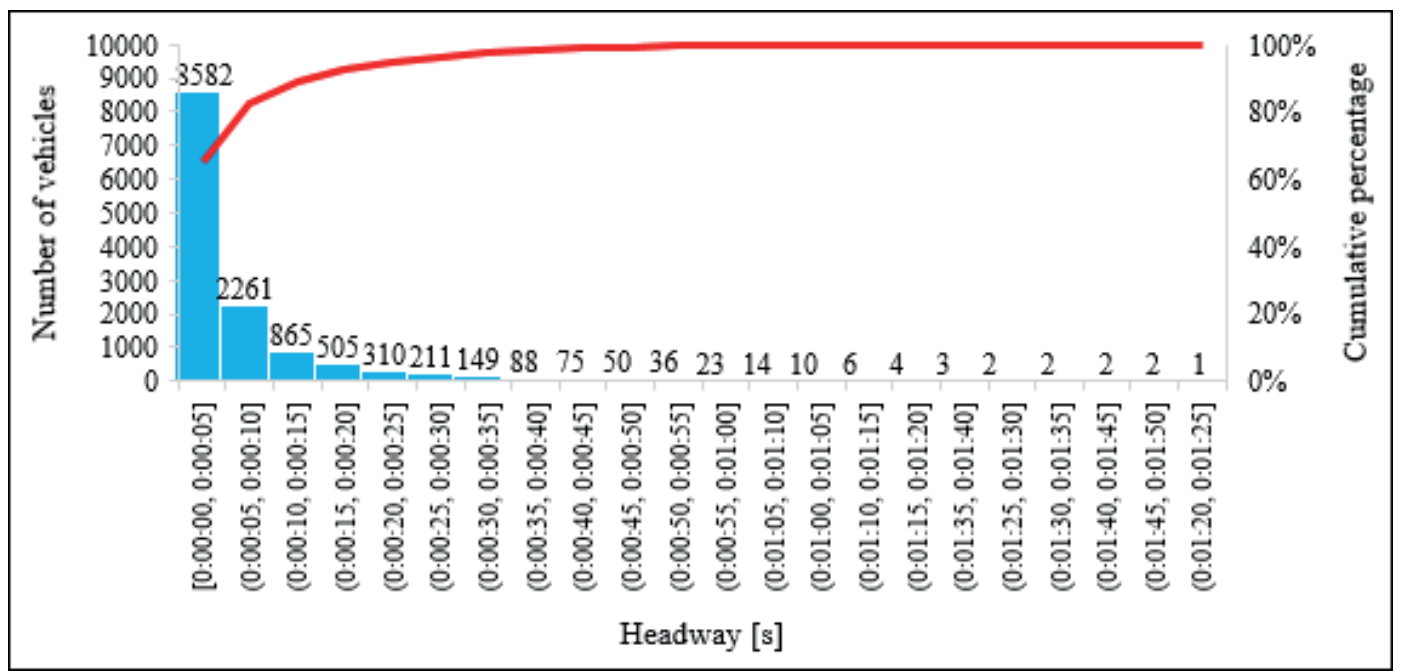

Figure 15 Division of headways into 5 sec intervals

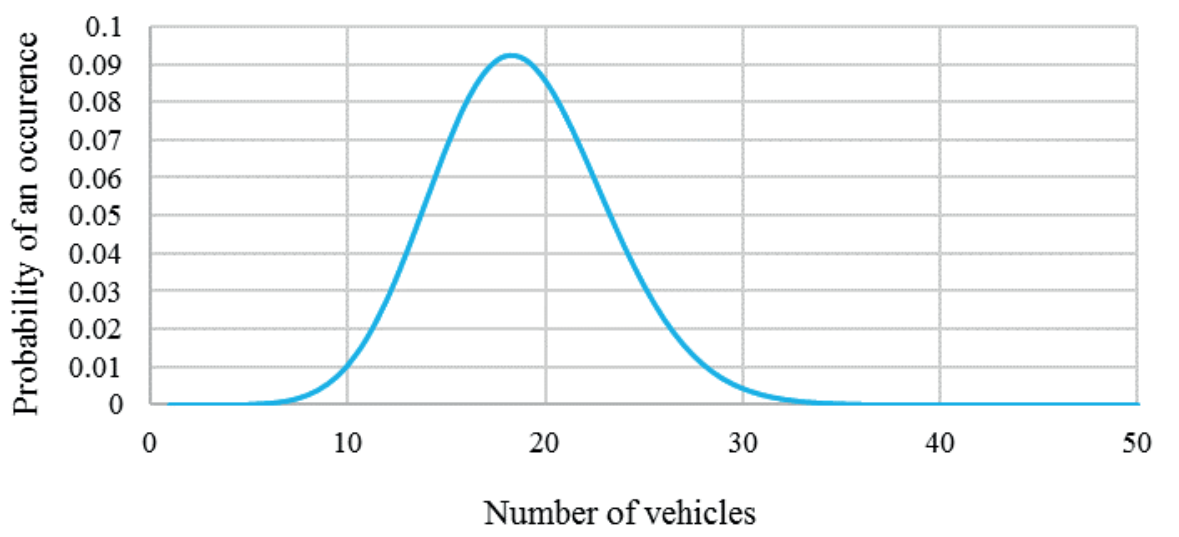

Figure 16 Probability of vehicles' occurrence during one minute of measurement

this measurement. In the speed class of $53-58 \mathrm{~km} / \mathrm{h}$, was obtained the highest number of vehicles. Considering that the maximum speed at this section of road is $50 \mathrm{~km} / \mathrm{h}$, more than $58 \%$ of vehicles exceeded the permitted speed. The speed median of $53 \mathrm{~km} / \mathrm{h}$ reached value, which was for 8 $\mathrm{km} / \mathrm{h}$ higher than the average one. The most often recorded value of speed was $55 \mathrm{~km} / \mathrm{h}$, also called as modus. This probability distribution of speed is called the normal or Gaussian distribution and it is one of the most important probability distributions of continuous stochastic variables [10, 23-25].

Time gaps between vehicles were divided into 26 classes with range of one class of $1 \mathrm{~s}$. The most often, gaps between vehicles were 1 and 2 seconds, subsequently 
their value decreased (Figure 14). The probability of unpredictable events occurrence, which affect time gaps between vehicles, has an exponential distribution. The next histogram of time lapses between vehicles (Figure 15) has the similar running, i.e. an exponential distribution.

Time lapses were divided to classes from $0 \mathrm{~s}$ to $85 \mathrm{~s}$, with class range of $5 \mathrm{~s}$ and the number of classes of 22 . The graphical representation in Figure 15 is called the Pareto diagram, which is a combination of histogram and line diagram. The line represents a cumulative multiplicity and gradually increases to $100 \%$. The most frequent time lapse was $5 \mathrm{~s}$, which was reached by 8582 vehicles. Approximately 50 vehicles had time lapse of more than a minute. The reason for this could be that vehicles have come in groups.

Figure 16 shows the graphical representation of the number of vehicles per minute, based on the Poisson distribution. According to statistics, that is a discrete probability distribution of occurrence of rare events in a series of a large number of independent experiments.

Based on the survey, there were recorded 18.8 vehicles per minute in average. Thus, the highest probability is that 18.8 vehicles per minute would pass the monitored road section in both directions $(\lambda)$ and, as the number of vehicles would increase or decrease, this probability decreases.

\section{Discussion}

As the number of automobile transport increases, density increases and speed of the traffic flow decreases. This fact has the effect on increase of the delay time, travel time and stop time. Mentioned characteristics of the traffic flow vary considerably, depending on time and volume of traffic, often reaching the maximum values. Intersections are the important points of the road network permeability.

Evaluation of transport survey revealed that the highest number of vehicles was recorded from 6:30 to 6:45 a.m., at intensity of 326 vehicles. The average intensity, according to survey results is 1200 vehicles per hour and according to simulation it is 1035 vehicles. The strongest correlation was observed in relationship of density and speed of value of - 0.95 , which represents a strong linear dependence. Results of relations between the basic characteristics showed that the traffic flow variables do not always behave according predefined relations. The basic theory behind the interaction is that congestion leads to higher vehicle densities (i.e., more closely spaced vehicles on a roadway), which provides more opportunities for a conflict. Congestion also reduces vehicle speeds. When vehicles are engaged in a crash, the collision forces are lower because of the lower speed and the negative consequences of an accident could be reduced for a driver, as well as for passengers. Another aspect of the model is the concept of "secondary" accidents - accidents that occur due to conditions produced by an existing crash. Some of those conditions - which would not exist without occurrence of the primary accident - include the rapid backward queue formation (as vehicles suddenly stop to avoid the primary accident), rubbernecking by drivers and manoeuvres of emergency vehicles. The details of the relationship between congestion and safety are not well understood.

\section{Conclusion}

- Based on the limited work that has been performed, a few tentative conclusions may be drawn:

- An accident occurrence probably increases as congestion increases.

- There is a lower proportion of single vehicle crashes (e.g., run-off-road, rollover, collision with fixed object) during the congestions, on the other side, there is a higher proportion of multiple vehicle accidents.

- Accident severities (extent and nature of personal injuries) are lower during the congestion, due to the lower vehicle speeds at the moment of crash impact.

In general, it can be assumed that any operational improvement that reduces congestion would lead to fewer accidents but the consequences of accidents could be harder related to the greater proportion of single vehicle crashes. Knowing these facts can target mitigation strategies to single vehicle crashes and higher severities - such as wider roadside recovery zones, protection on highways and coordination with emergency medical services. Moreover, an operations philosophy must take a systems-oriented view, where the consequences of a specific action must consider the related impacts, such as safety.

\section{Acknowledgment}

This contribution is made within project VEGA 1/0436/18 Externalities in road transport, an origin, causes and economic impacts of transport measures.

This contribution is the result of the project implementation: Centre of excellence for systems and services of intelligent transport II, ITMS 26220120050 supported by the Research \& Development Operational Programme funded by the ERDF.

\section{References}

[1] SCHREYER, CH., SCHNEIDER, CH., MAIBACH, M., ROTHENGATTER, W., DOOL, C., SCHMEDDING, D. External costs of transport. Update study, Paris: International Railway Union, 2004. ISBN 2-7461-0891-7.

[2] SYNAK, F., CULIK, K., RIEVAJ, V., GANA, J. Liquefied petroleum gas as an alternative fuel. Transportation Research Procedia [online]. 2019, 40, p. 527-534. ISSN 2352-1465. Available from: https://doi.org/10.1016/j.trpro.2019.07.076 
[3] KUHNE, R. Foundations of traffic flow theory I: Greenshields' Legacy - highway traffic. In: Symposium on the Fundamental Diagram: 75 Years - Greenshields 75 Symposium: invited presentations. Massachusetts, United States: Committee on Traffic Flow Theory and Characteristics, 2008.

[4] NI, D. Traffic flow theory: characteristics, experimental methods and numerical techniques. 1. ed. Elsevier, 2015. ISBN 978-0128041345, eISBN 9780128041475.

[5] KESSELS, F. Traffic flow modelling: introduction to traffic flow theory through a genealogy of models [online]. Berlin Heidelberg: Springer-Verlag, 2019. ISBN 978-3-319-78694-0, eISBN 978-3-319-78695-7. Available from: https://doi. org/10.1007/978-3-319-78695-7

[6] KALASOVA, A., STACHO, M. Decrease in congestions is one of the most important factors for increase in safety in road transport. In: Modern Safety Technologies in Transportation: proceedings. 2005. ISBN 80-969106-1-2.

[7] KALASOVA, A., FAITH, P., PALO. J. Transportation Engineering I / Dopravne inzinierstvo I (in Slovak). Zilina: University of Zilina, 2006. ISBN 80-8070-634-4.

[8] LEUTZBACH, W. Introduction to the theory of traffic flow [online]. Berlin Heidelberg: Springer-Verlag, 1988. ISBN 9783-642-64805-2, eISBN 978-3-642-61353-1. Available from: https://doi.org/10.1007/978-3-642-61353-1

[9] TREIBER, M., KESTING, A. Traffic flow dynamics [online]. Berlin Heidelberg: Springer-Verlag, 2013. ISBN 978-3-64232459-8, eISBN 978-3-642-32460-4. Available from: https://doi.org/10.1007/978-3-642-32460-4

[10] Relations between the basic characteristics of the traffic flow / Vztahy zakladnich charakteristik dopravniho proudu (in Czech) [online] [accessed 2020-02-02]. Available from: http://kds.vsb.cz/krivda/www-di(vb3-dos)/02-dopr-proud.pdf

[11] List of countries by road network size - Wikipedia [online] [accessed 2020-02-23]. Available from: https://en.wikipedia. org/wiki/List_of_countries_by_road_network_size

[12] CULIK, K., KALASOVA, A., KUBIKOVA, S. Simulation as an instrument for research of driver-vehicle interaction. MATEC Web of Conferences [online]. 2017, 134, 00008 [accessed 2020-02-03]. eISSN 2261-236X. Available from: https:// doi.org/10.1051/matecconf/201713400008

[13] ITE (Institute of Transportation Engineers), WOLSHON, B., PANDE, A. Traffic engineering handbook. 7. ed. Wiley Network, 2016. ISBN 978-1-118-76230-1.

[14] Transport Yearbook 2018 / Rocenka dopravy 2018 (in Czech) [online] [accessed 2020-02-03]. Available from: https:// www.sydos.cz/cs/rocenka-2018/rocenka/htm_cz/cz18_321000.html

[15] Strategic plan for transport development in the Slovak republic until 2030 / Strategicky plan rozvoja dopravy SR do roku 2030 - Ministry of Transport and Construction of the Slovak Republic (in Slovak) [online] [accessed 2020-0113]. Available from: https://www.mindop.sk/ministerstvo-1/doprava-3/strategia/strategicky-plan-rozvoja-dopravy-sr-doroku-2030

[16] Statistical Office of the Slovak Republic [online] [accessed 2020-02-08]. Available from: https://slovak.statistics.sk/

[17] POLIAK, M. The relationship with reasonable profit and risk in public passenger transport in the Slovakia. Ekonomicky Casopis. 2016, 61(2), p. 206-220. ISSN 0013-3035.

[18] Sierzega radar [online] [accessed 2020-02-12]. Available from: https://www.sierzega.com/en-us/home

[19] BARCELO, J., CODINA, E., CASAS, J., FERRER, J. L., GARCIA, D. Microscopic traffic simulation: a tool for the design, analysis and evaluation of intelligent transport systems. Journal of Intelligent and Robotic Systems [online]. 2005, 41(2), p. 173-203. ISSN 0921-0296. Available from: https://doi.org/10.1007/s10846-005-3808-2

[20] KRBALEK, M. Equilibrium distributions in a thermodynamical traffic gas. Journal of Physics A: Mathematical and Theoretical [online]. 2007, 40, p. 5813-5821. ISSN 1751-8113, eISSN 1751-8121. Available from: https://doi. org/10.1088/1751-8113/40/22/004

[21] Open Street Maps [online] [accessed 2020-02-01]. Available from: https://www.openstreetmap. org/\#map=15/49.0588/18.9322

[22] TSS - Transport Simulation Systems. Microsimulator and Mesosimulator Aimsun 8.1 User's manual.

[23] Total number of registered cars - Car sales statistics [online] [accessed 2020-02-05]. Available from: https://www.bestselling-cars.com/germany/2018-germany-total-number-registered-cars

[24] ONDRUS, J., KOLLA, E. The impact of ABS system on the braking characteristics of the specified motorcycle on the dry road surface. IOP Conference Series: Materials Science and Engineering [online]. 2018, 421(2), p. 1-11 [accessed 2020-01-19]. ISSN 1757-8981, eISSN 1757-899X. Available from: https://doi.org/10.1088/1757-899X/421/2/022024

[25] ONDRUS, J., CERNICKY, L. Usage of Polcam device for parameter monitoring and traffic flow modelling. Communications: Scientific Letters of the University of Zilina [online]. 2016, 18(2), p. 118-123. ISSN 1335-4205, eISSN 2585-7878. Available from: http://komunikacie.uniza.sk/index.php/communications/article/view/342 